\title{
Career Transitions of K-12 Teachers to Full-Time Faculty Positions in Higher Education and Its Impacts on Social Justice
}

\author{
Priva Fischweicher, Jean M. McAtavey, David M. Kopp \\ Barry University, USA
}

\begin{abstract}
The responsibility to provide individuals the tools necessary to be productive members of society has been the province of $\mathrm{K}-12$ education. Viewing the equitable distribution of educational opportunities visà-vis a social justice lens helps to explain the obstacles to achieving the above stated goal. Yet, the providers of said tools, teachers, are leaving the $K-12$ education system at an alarming rate. Some of these teachers choose to continue as educators, but in a different educational arena, as full-time faculty in institutions of higher education. In response to this phenomenon and to better understand why $\mathrm{K}-12$ teachers are transitioning out of $\mathrm{K}-12$ education, a phenomenological study was conducted to explore the lived experiences of K-12 teachers who made a career transition and became full-time university faculty members.
\end{abstract}

\section{Introduction}

Social justice underpins the equitable delivery of education to all student vis-à-vis the resources necessary to achieve that goal. Free, public K-12 education is a universal right in the United States (U.S), nonetheless, as has been underscored in Kozol's book Savage Inequalities, and articles by Darling-Hammond and Schmidt and McKnight, for decades, inequity in K-12 schools in the U.S. has continued unabated. In a democracy, where the most recent reports (2011-2012) on U.S. Census data revealed that $12.9 \%$ of the population was foreign born, and $36.8 \%$ of those individuals were living below the poverty line, the issue of inequity in K-12 education remains a problem and needs to be addressed in order to provide all students in that educational environment the tools necessary to become productive members of society.

Research studies have highlighted the crucial role teachers play in providing students with the tools necessary to become contributing members of society [18]. Nonetheless, results from a 2007 study conducted by the National Commission on Teaching and America's Future indicated a 50\% increase in the attrition rate of teachers leaving K-12 education over the past 15 years. This is particularly a concern in urban schools where teacher attrition rates as high as $20 \%$ have been found.

The problem of teachers leaving K-12 education is not unique to the U.S. In Canada, teacher turnover is a recurrent problem with more than $60 \%$ of Ontario school boards reporting problems with teacher retention and $19 \%$ of beginning teachers being classified as at-risk for leaving the profession within their first three years of employment [15]. Clearly, there is a need to understand how to retain these teachers in order to provide a more equitable educational experience for all K-12 students.

Although there is a plethora of research on career transitions including the causes of work role transitions [3] and mid-life career transitions [14], there is a dearth of research addressing teacher career transitions, particularly K-12 teachers who remain in education but transition to teach in institutions of higher education. Thus, the purpose of this qualitative phenomenological study was to understand why teachers made a career transition from K-12 schools to become full-time faculty in higher education institutions. 


\section{Relevant Literature on Career Transitions}

Historically, career paths have been linear with individuals moving up the hierarchical ladder within the same organization. The purpose of this transition to a different or higher position is to obtain a greater extrinsic reward [23].

Yet, the global economy, technological advances, increased diversity within the workforce, the use of parttime and temporary employees have impacted the traditional career transition trajectory. In addition, people are making career changes based on personal considerations including changing family structures, or a desire for personal learning and development leading to more emphasis on self-directed career choices [19].

This phenomenon was noted in the 1990s, and the concept of boundaryless career transitions evolved. The boundaryless career concept entails non-linear transitions premised on aspects of individual independence. This results in moving away from traditional career trajectories within the boundaries of one specific organization [23].

\subsection{K-12 Teachers and Career Transitions}

Effective teachers are one of the most valuable resources in any educational system as they are the ones delivering the product, knowledge and skills, to the customer base, students. This is demonstrated in studies that show the positive impact of effective teachers on academic achievement of students [18].Yet, teachers are transitioning out of the K-12 system at an alarming rate. According to a 2007 study conducted by the National Commission on Teaching and America's Future, the attrition rate was $16.8 \%$, with rates as high as $20 \%$ in some urban school districts. The proportion of teachers leaving this educational arena in the last 15 years increased by $50 \%$. In addition, the cost of $\mathrm{K}-12$ public school teacher turnover was in excess of $\$ 7.3$ billion a year [15].

In Canada, similar challenges are evident. Within the first five years of a teaching career, the reported range of attrition was 5-25\% [4].

A research study by Ronfeldt, Loeb, and Wyckoff investigated the impact of teacher turnover on the academic success of their students. The findings suggest that students are negatively impacted by this phenomenon, resulting in lower test scores [21].
Another study with a similar conclusion found that the stability of the teaching staff correlated with student achievement [10]. Yet, some of our most experienced teachers are leaving K-12 education to become fulltime university professors.

\section{Relevant Literature on Social Justice}

Rawls in his seminal text A Theory of Justice, espoused the ability of individuals to realize their potential within society as an integral component of social justice [19]. In order to actualize this goal, major social institutions would equitably distribute fundamental rights and resources to all members of society. This concept, often referred to as distributed justice, is viewed from two dimension, equality of opportunity and equality of outcome [11]. In reference to equality of opportunity, Lynch stated that failure is acceptable if everyone is given the same opportunity to succeed. Yet, Young posited that social justice reached beyond the allocation of resources within society and it was important to consider the injustices which bind the underserved [26].

\subsection{Social Justice and Education}

The construct of social justice has become pervasive within the dialogue of education. According to Hytten and Bettez, many schools include social justice as part of their mission statement. An article by Zeichner discussed social justice in reference to remodeling teacher training programs. Yet, in 2006, the National Council for Accreditation of Teacher Education removed the term social justice from their standards due in part to the ambiguity associated with the construct.

Nonetheless, the equitable distribution of resources which is integral to social justice [19] is not a reality in the K-12 educational system, particularly in schools with high levels of students who qualify for free or reduced lunch [5].

Effective teachers are one of the most valuable resources in any educational system. This is demonstrated in studies that show the positive impact of effective teachers on academic achievement of students $[19 ; 20]$. Yet, some of our most experienced K-12 teachers are making career transitions and taking new opportunities as full-time faculty at institutions of higher education. 
A research study by Ronfeldt, Loeb, and Wyckoff investigated the impact of teacher turnover on the academic success of their students. The findings suggest that students are negatively impacted by this phenomenon resulting in lower test scores [21]. A similar conclusion was reached in a study conducted by Heck which found that the stability of the teaching staff correlated with student achievement [12].

\section{Theoretical Framework}

The theoretical framework for this study was the Theory of Work Adjustment (TWA). The need to understand how people relate to the work they are engaged in was a driving force behind the development of this theory [7]. A major premise of TWA is that successful careers require a good fit between individuals and their work environment. This fit is termed correspondence. The level of an individual's job satisfaction job directly correlates to the perceived degree of correspondence. There is a dynamic process termed "work adjustment" wherein individuals continuously strive to achieve and maintain correspondence with the environment. Yet, when the degree of correspondence is low, individuals tend to leave that work environment [7].

\section{Research Methods and Data Sources}

This qualitative study was conceptualized within the phenomenological tradition. This research design was chosen as it allowed the voices of the participants who experienced the phenomenon being studied to be heard [6]. This aligns with the ontological assumption that participants' individual thoughts and feelings about the phenomenon would emerge in their responses to the open-ended questions.

The philosophical perspective guiding this study was social constructivism. This choice was premised on the emphasis social constructivism places on the distinct experiences of each participant based on his/her unique position or societal role [17].

\subsection{Research Questions}

The research questions underpinning this study is as follows:
5.1.1. Research question one: Why are $\mathrm{K}-12$ teachers making a career transition to become full-time faculty in higher education institutions?

5.1.2. Research question two: What is the effect, from a social justice lens, of K-12 teachers making a career transition to full-time faculty in higher education institutions?

\subsection{Participants}

Prior to contacting participants and collecting data, the researchers submitted the required Protocol to their university's Institutional Review Board (IRB). After receiving approval from the IRB, a purposive sampling method was used.

Participants who were employed in the southeastern area of the United States were selected for this study. Full-time faculty members from either public or private four-year institutions of higher education were invited to participate in this research. A criterion for participation was that an individual had to have taught in the K-12 system and left that career prior to transitioning to a position as a full-time faculty member at a college or university.

Individuals who met the research criteria were contacted and invited to participate in the study. This entailed completing a web-based demographic survey and responding to six open-ended questions. The narrative responses to the open-ended questions allowed the participants' own contextualized stories to emerge [6].

\section{Data Analysis}

Data was collected and analyzed from the first 10 participants who responded to the survey. The data from the open-ended questions was coded to aid in the identification of patterns across the responses. The researchers, through the use of inductive reasoning, interpreted the data and extracted themes as empirical evidence of the participants' perceptions based on their lived experience of the phenomenon being studied [6].

\section{Findings}

Findings from this qualitative study highlighted the participants' positive experiences during their 
career as K-12 teachers as well as why they left that educational environment and transitioned into fulltime faculty positions in higher education. In addition, the demographic survey portion of this study exposed a propensity of experienced teachers who selfidentified as minorities leaving the K-12 educational system. The findings underscore the challenges of providing an equitable education environment for all K-12 students when viewed through a social justice lens.

\subsection{Demographic Findings}

In terms of race/ethnicity, the study participants identified themselves as follows: $40 \%$ Black/AfricanAmerican, 10\% Hispanic, 20\% White/Caucasian, and $20 \%$ as multiracial or other.

According to Noguera Black/African American and Hispanic males independent of whether the school is situated in an urban, rural, or suburban setting have a higher propensity than any other group to display problems that result in suspension or expulsion from school [16]. The dropout rate of this population is greater than $50 \%$ in most school districts in the U.S. [22]. Yet, the issue of social economic status (SES) appears to have little effect on academic achievement as reported in a 2010 study by the Schott Foundation for Public Education. Results from the study found middle class Black/African American and Hispanic males lagging behind their White counterparts on grade point average and scores on standardized tests [22].

The importance of same-race teachers on academic success of minority students may have a mitigating effect on this population and has found support in the literature. Research by Dee found that when students were assigned to same-race teachers their academic achievement in math and reading increased significant [8]. A study by Casteel found that Caucasian American teachers interacted less frequently with African-American students and had more negative interactions [2]. This issue exposes the social justice component inherent in unequal educational opportunities for minority students.

The preponderance of non-White/Caucasian participants in our study underscores the need to find ways to retain racially diverse teachers in $\mathrm{K}-12$ so they can serve as role models to students in that educational environment. This recommendation is based on same-race teachers' impact on student academic success, retention, and persistence [2;8].

Additional information garnered from the demographic survey revealed that $70 \%$ of the study participants had taught a minimum of 11 years in the K-12 system while the remainder reported teaching between one and five years. These results may be important to teacher retention as it relates to several issues including the effect on students of less experienced teachers in classrooms and the related issue of teacher sorting. All of these issues directly relate to the social justice aspect inherent in a system that strives to deliver an equitable quality of education to all students.

The issue of length of time in the profession, often referred to as teacher experience, has been shown to effect students' academic achievement. A study by Grissmer, Flanagan, Kawata and Williamson found teachers with work experience in the specific area they were teaching had a greater impact on student achievement than teachers with master's degrees [10].

The need to retain experienced teachers is underscored by research that determined that new teachers need at least five to six years of teaching experience to attain the following goals: confidence and the ability to effectively implement classroom procedures; develop interesting, organized, and effective lessons; and fully integrate into the school's culture [9]. Retaining experienced teachers may help to mitigate K-12 students' academic challenges.

In addition, the practice of teacher sorting, placing less experienced, less effective/highly qualified teachers in lower performing schools has been extensively documented [13]. Data from the U.S Department of Education Office of Civil Rights revealed that $3-4 \%$ of minority students attend schools with higher concentrations of first-year teachers. This statistic contrasts with $1 \%$ of White students who find themselves in classrooms with first-year teachers [24].

The transition of experienced teachers out of the K-12 educational system appears to exacerbate the academic challenges of lower SES minority students. This is especially true when viewed through a social justice lens.

\subsection{Qualitative Findings}

Several findings from this qualitative study may help to explain why $\mathrm{K}-12$ teachers are leaving that educational environment and are transitioning to 
careers in higher education as full-time faculty. In addition, the results mirror those discussed in the section on demographic findings, and highlight the quality/effectiveness of the study participants vis-à-vis their role as teachers, thus the imperative to find ways to retain them in the $\mathrm{K}-12$ system.

7.2.1. Lack of academic freedom. According to Weiler and Maher the emphasis on standardized testing and packaged curriculum has impacted the role of K-12 teachers [25]. The responses of our study participants aligned with this finding. This is demonstrated by their quotes concerning curriculum issues and levels of accountability they encountered when teaching in K-12 schools:

"Became frustrated at teaching each in ever[y] class in a scripted fashion."

"Challenging and extremely restrictive! I could not be creative and felt bound to lesson planning and styles."

"In the current climate, K-12 settings... are becoming more and more similar especially in the arena of accountability."

"The inability to use my skills, knowledge, and experience to help my students because of the prescribed curriculum was very demeaning."

"Insisting on set curriculum without any input from experienced teachers was the final impetus for me to leave K-12 to teach at the university level."

"Too much control over the curriculum by administration with little input from teachers."

Five participants mentioned the level of academic freedom in higher education as one of the factors for their decision to make a career transition.

"In higher ed... you have some freedom."

"The ability to teach in a way I find to be advantageous became a reality when I became a professor."

"Teaching in my previous K-12 school required using a standard curriculum. Here at the university I am given the flexibility to use my talents."

"What a difference, at the university I am encouraged to be creative and facilitate my courses in a way that I know better meets the need of my students."

"The level of academic freedom that is found at the university no longer existed when I decided to leave K-12 education. In this environment I am able to create my own syllabi including learning activities and assessments."

I find higher ed to be more professional and serious. It is sad to me that teachers in $\mathrm{K}-12$ settings are not treated overall with respect from their administrators and at times parents. The culture of higher ed is more professional...more horizontal in the decision making than in K-12 settings that still uses a more vertical approach where teachers are at the bottom of the decision making process.

Standardized testing was also mentioned by several participants as one of the challenges they experienced as teachers in the K-12 system.

"Expecting academic growth based on grades and testing without taking into consideration factors not within my control as a teacher was frustrating."

7.2.2. Teacher effectiveness. Teacher effectiveness has been found to impact on student achievement [12], thus the need to keep effective teachers in the K-12 system. Characteristics of teacher effectiveness include optimism and the ability to engage high academic engagement and competence [as cited in 27]. Study participants' effectiveness was highlighted by the following responses:

I am passionate about teaching especially when it comes to students who are at risk of failing or dropping out of school. Though the factors that contribute to this might be numerous, we as teachers don't often reflect on whether or not we contribute to it by the way, how we plan for instruction.

"Helping students master the course content."

I continue to try to individualize my work with students at the University, and though not always expected, find great satisfaction from teaching others the knowledge and skills they didn't know previously and then watching them apply those skills in other situations.

"Addressing the learning needs of all my students." 
"I continue to guide, instruct, support, and care for students."

"Since coming to the university, I feel reenergized. I am able to actually make a difference in my students' lives."

"I enjoyed interacting with the students and witnessing their progress over the semester."

"I am respected for my ability as an educator by students, colleagues, and administrators."

Looking at participants' responses from a different perspective, teachers who transitioned from K-12 to higher education discussed the impact they hoped to make on future K-12 teachers.

I have seen students regress because teachers fail to provide effective instruction, cannot exhibit adequate classroom behavior management, and implement motivational strategies. Therefore, I decided to transition to higher education because in this capacity, I can challenge my pre-service and inservice teachers to make a positive impact on their students. I am able to encourage them to develop their own teaching philosophy about best practices which they can transfer into their own practice.

What helped me the most were my many year of experience as an elementary school teacher. I was able to bring my wealth of knowledge to my education students in higher ed. My success with my education students has been in my ability to share my survival tips, pedagogical strategies, and curriculum knowledge with them

"I feel I could make a greater impact at the college level by teaching prospective teachers in my specialization area."

"Can speak from experience - been there, done that"

I also think that my intrinsic motivation to excel was the driving force that propelled me into higher education where I can make a greater impact on student achievement. For example, if I were to teach 50 students in an academic year and after graduation they have their own students then implicitly I have impacted more students than if I had a single class of $\mathrm{K}-12$ students each year.

\section{Scholarly Significance}

The results garnered from this study may help to explain why K-12 teachers are transitioning out of that educational environment. The lack of academic freedom and the expanding levels of accountability appear to have played a role in K-12 teachers seeking a different educational environment in which to continue their career. These findings align with those of Weiler and Maher who found that packaged curriculum and standardized testing had an impact on the role teachers play in K-12 schools [25].

The results also appear to align with the theoretical framework underpinning this study, the Theory of Work Adjustment. A lack of correspondence between the participants and their work environment may have impacted on their decision to leave the K-12 educational environment.

In order to provide the best learning experience for K-12 students vis-à-vis a social justice perspective, it is imperative that effective teachers be retained in the K-12 system. For as Heck stated, teacher effectiveness has a profound impact on the academic achievement of students [12]. Yet, based on the results of this study, teachers of this caliber appear to be leaving the K-12 educational arena to continue their careers at colleges or universities.

Yet, there may be one positive effect when K-12 teachers' transition to become full-time faculty in colleges and universities, the impact these experienced faculty members may have on future K-12 educators. This may help in some way to mitigate the social justice concerns related to their transitioning out of the $\mathrm{K}-12$ educational environment.

\section{Further Research}

This study was limited to participants from the southeastern portion of the United States. Expanding this research to other geographic locations may allow for greater levels of transferability of the findings.

In addition, the study was limited to ten participants, increasing that number would allow additional voices to be heard and their lived experiences to be incorporated into the findings.

Including a quantitative element to the study by using a career transition and/or a social justice survey 
instrument may allow for triangulation of the findings and increase the validity, reliability, and generalizability of the results.

\section{References}

[1] Canadian Teachers' Federation. (2000). Demographics of the teaching profession: The changing nature of teaching in Canada. Ottawa: CTF.

[2] Casteel, C. A. (1998). Teacher-student interactions and race in integrated classrooms. The Journal of Educational Research, 92(2), 115-120.

[3] Chudzikowski, K. (2012). Career transitions and career success in the 'new' career era. Journal of vocational behavior, 81(2), 298-306.

[4] Clark, R., \& Antonelli, F. (2009). Why teachers leave: Results of an Ontario survey 2006-2008, Ontario Teachers' Federation.

[5] Condron, D. J. \& Roseigno, V. J. (2003). Disparities within: Unequal spending and achievement in an urban school district. Sociology of Education, 76(1), 18-36.

[6] Creswell, J. W. (2009). Research design: Qualitative, quantitative, and mixed methods approaches ( $3^{\text {rd }}$ ed.). Thousand Oaks, CA: Sage.

[7] Davis, R. V., Lofquist, L. H., \& Weiss, D. J. (1968). A theory of work adjustment (a revision). Minnesota Studies in Vocational Rehabilitation, 23.

[8] Dee, T. S. (2004). Teachers, race, and student academic achievement in a randomized sample. The Review of Economics and Statistics, 86(1), 195-210.

[9] Glasgow, N. A., \& Hicks, C. D. (2003). What successful teacher do: 9 research based classroom strategies for new and veteran teachers. Thousand Oaks, CA: Corwin Press.

[10] Grissmer, D., Flanagan, A., Kawata, J., \& Williamson, S. (2000). Improving student achievement: What state NAEP test scores tell us (Rand Monograph Report No. MR924-EDU).

[11] Gewirtz, S. (2006). Conceptualizing social justice in education: Mapping the territory. Journal of Education Policy, 13(4) 469-484.

[12] Heck, R. H. (2009). Teacher effectiveness and student achievement: Investigating a multilevel cross-classified model. Journal of Educational Administration, 47(2), 227249.
[13] Lankford, H., Loeb, S., \& Wyckoff, J. (2002). Teacher sorting and the plight of urban schools: A descriptive analysis. Educational Evaluation and Policy Analysis, 24, 37-62.

[14] Liu, Y., Englar-Carlson, M., \& Minichiello V. (2010). Midlife career transitions of Men who are scientists and engineers: A narrative study. The Career Development Quarterly, 60, 273-288.

[15] National Commission on Teaching and America's Future. (2007). The high cost of teacher turnover. Washington, D.C.: Author.

[16] Noguera, P.A. (2012). Saving Black and Latino boys: What schools can do to make a difference. Kappan, 95(5), 8-12.

[17] Patton, M. Q. (2002). Qualitative research and methods. (3rd ed.). Thousand Oaks, CA: Sage.

[18] Qsureshi, M. A., \& Niazi, H. K. (2012). Impact of effective teachers on students' academic achievements. Journal of Educational Research, 15(1), 30-38.

[19] Rawls, J. (1971). A theory of justice. Cambridge, MA: Belknap Press of Harvard University Press.

[20]Rockoff, J. E. (2004). E. (2004). The impact of individual teachers on student achievement: Evidence from panel data. American Economic Review, 94(2), 247-252.

[21] Ronfeldt, M., Loeb, S., \& Wyckoff, J. (2013). How teacher turnover harms student achievement. American Educational Research Journal, 50(1), 4-36.

[22] Schott Foundation for Public Education. (2010). The Schott 50 state report on public education and black males. Cambridge, MA: Author.

[23] Sullivan, S. N., \& Baruch, Y. (2009). Advances in career theory and research: critical review and agenda for future exploration. Journal of Management, 35(6), 1452571.

[24] U.S Department of Education Office of Civil Rights (2011). Teacher Equity. Retrieved from offices/list/ocr/docs/crdc-teacher-equity-snapshot.pdf

[25Weiler, K., \& Maher, F. (2002). Teacher education and social justice. Radical Teacher, 64, 2-4.

[26] Young, I. M. (1990). Justice and politics of difference. Princeton, NJ: Princeton University Press. 